\title{
Determination of Antidepressant Drug Use Among Inpatients in Medical and Surgical Clinics
}

\author{
Elvan Emine Ata ${ }^{1}$ iD, Emel Bahadir Yilmaz² \\ ${ }^{1}$ Giresun University School of Health Sciences, Department of Nursing, Giresun, Turkey \\ ${ }^{2}$ Giresun University School of Health Sciences, Department of Midwifery, Giresun, Turkey \\ Correspondence Author: Elvan Emine Ata \\ E-mail: elvanhenden@gmail.com \\ Received: $01.02 .2017 \quad$ Accepted: 10.04 .2017
}

\begin{abstract}
Objective: This cross-sectional study was performed to determine antidepressant drug use among inpatients in medical and surgical clinics. Methods: The study sample consisted of 478 inpatients from a state hospital, between December 1, 2015 and January 1, 2016. The information form was applied to the patients. Number and percentage distribution were used for data analysis.

Results: Of the 478 patients, $34.5 \%$ had visited a psychiatrist once in their lifetime, $13.6 \%$ were diagnosed with depression, and $13.8 \%$ did not know the diagnosis of mental disease; $32.2 \%$ were suggested medication by their doctor, $16.7 \%$ did not know the name of this medication, and $13.2 \%$ stated that the suggested drug was antidepressant. Moreover, $24.9 \%$ of the patients were known to use antidepressant at least once in their lifetime, and $16.3 \%$ were still using antidepressants. Among patients using antidepressants, $32 \%$ continued using this drug upon doctor's recommendation and $13.6 \%$ continued with the diagnosis of depression.

Conclusion: It might be concluded that one-fourth of the patients used antidepressant once in their lifetime; more than one-half of these patients were still using antidepressants, and most of them were using the drug upon doctor's recommendation without any knowledge about antidepressants.
\end{abstract}

Keywords: Antidepressant drug, nursing, patient

\section{INTRODUCTION}

According to the Economic Policy Research Foundation of Turkey, the rate of antidepressant use increased $65 \%$ in the last 5 years. The consumption was 20 million boxes in 2005 and increased over 34 million in 2010. Antidepressant consumption was 0.29 boxes per capita in 2005, but it increased to 0.45 in 2010 (1). According to the Intercontinental Marketing Service (IMS) data, the growth rate of the antidepressant sales was $160 \%$ in the last 9 years in Turkey (2). This increase might be a result of prescriptions by physicians other than psychiatrists and over the counter sales. Psychiatric consultation requested for the hospitalized patients in the departments of the internal medicine, surgery, and physiotherapy might also be responsible for the growth in the consumption of antidepressants. Recent studies have reported that there was an increase in the psychiatric consultations, and depression was one of the most common diagnoses during these consultations; consequently, the use of the antidepressant drugs was increased (3-5). The consultation was requested mostly by the departments of internal medicine, neurology, neurosurgery, physiotherapy and rehabilitation, and pulmonology.

Investigation of the studies focused on psychiatric consultation revealed that the most common diagnosis related to the psychiatric diseases was depressive disorders, and the most commonly recommended drugs for the treatment of this disease were antidepressants (3-7). As the most common diagnosis among the hospitalized patients was depression, antidepressants were inevitably the most frequently used medications. Nevertheless, the frequent use of this drug group might be associated with certain problems. Several studies in the literature have demonstrated the emergence of extremely severe side effects related to antidepressants. The analysis of these studies showed following side effects encountered: dry mouth, constipation, weight gain, diarrhea, insomnia, yawning, urination problems, drowsiness, headache, and nausea $(8,9)$. Of the available studies, Ashton et al. (10) reported that patients prescribed treatment for depression reported "gained a lot of weight," "unable to have an orgasm," "lost interest in sex," "unable to have erection," and "tired during the day" (10).

In addition to these severe side effects, uncontrolled use and misuse of the antidepressive agents might cause life-threatening complications. Studies have shown that antidepressants were one of the most frequently encountered drugs in intoxication cases (11-13). Furthermore, according to the investigations, antidepressants were preferred for suicide 
in $74.4 \%$ attempts (11). In light of these data, we believe that it becomes important to determine how patients access these drugs, whether there is a real need for their use, and who are prescribing them. Treatments administered by the physicians (except psychiatrists) were often insufficient regarding the appropriate and required dosage and the treatment duration. Consequently, the disease became often chronic with labor loss, and mortality increased due to emergence of the untreated disease (2). In light of this information, it should be emphasized that physicians should be more cautious during the diagnosis and prescription of the antidepressive agents. Additionally, it should be considered that nurses responsible for the execution of the physicians' orders also have a major responsibility for the implementation the treatment (14). It is also necessary that nurses inform patients about the side effects, what should be done if the side effects occur, importance of consistent compliance with the treatment, interactions with other substances, periodic tests, time of the onset of the action, and the importance of gradual discontinuation of the treatment (15). We believed that this study would be an important step in indicating the current condition related to antidepressant use and in determining the way for solving the detected problems. In this regard, our objective was to find out the antidepressant use among hospitalized patients in the clinics of internal medicine and surgery.

\section{METHODS}

\subsection{Study Design}

This study was a cross-sectional, descriptive survey design. Subjects In total, 478 hospitalized patients treated in the internal medicine and surgery clinics of the Giresun Prof. Dr. IIlhan Özdemir Public hospital between December 1, 2015 and February 1, 2016 were included and consented voluntarily to participate in the study.

\subsection{Materials}

Investigators prepared an information form for the patients, which was in line with the relevant literature $(2,3,9,16$ 18). The information form contained 33 questions referring the demographic characteristics of the patients, such as the age, gender, and education status and other characteristics, such as visiting a psychiatrist, antidepressant use, and encountered side effects.

\subsection{Process}

Before the start of the study, approvals of the administration of the Giresun Prof. Dr. İlhan Özdemir Public hospital and the ethics committee of the General Secretary of the Giresun Prof. Dr. İlhan Özdemir Public Hospitals Union were obtained. The study was conducted according to the principles of the Helsinki Declaration. Furthermore, every patient was informed about the objective of the study. It was explained that they could chose to discontinue from the study at anytime and this act would not affect their treatment. Written consent was also obtained. The enrolled patients (who met the inclusion and exclusion criteria of the study) were questioned within the first week of their hospitalization in their rooms while they were alone.

Inclusion criterias were age $>18$ years, treatment in the hospital, stay at hospital at least 1 week, no difficulty in communication. Exclusion criterias were stay at hospital $<7$ days, outpatient, unconscious patients.

\subsection{Statistical Analysis}

Statistical Package for Social Sciences (SPSS In.; Chicago, IL, USA) for Windows, version 16.0, was used for data entry and analysis. The analysis was conducted with numeric and percentage distribution.

\section{RESULTS}

Some of the characteristics of the patients are summarized in Table 1; $29.9 \%$ of the patients were in the age group of $41-$ 60 years, $52.1 \%$ were females, $47.9 \%$ were primary school graduates, and $84.5 \%$ were not working. In addition, $45.8 \%$ of the patients were known to live in small towns, and $53.9 \%$ had an income equal to their expenditure (Table 1 ).

Table 1. Patient characteristics

\begin{tabular}{|l|l|l|l|}
\hline \multirow{4}{*}{ Age group } & $\leq 20$ years & 4 & 0.8 \\
& 21-40 years & 49 & 10.3 \\
& $41-60$ years & 143 & 29.9 \\
& 61-80 years & 186 & 38.9 \\
& $\geq 81$ years & 96 & 20.1 \\
\hline \multirow{2}{*}{ Gender } & Female & 249 & 52.1 \\
& Male & 229 & 47.9 \\
\hline \multirow{2}{*}{ Educational } & Illiterate & 184 & 38.5 \\
& Primary school & 229 & 47.9 \\
& Middle school & 32 & 6.7 \\
& High school and university & 33 & 6.9 \\
\hline \multirow{2}{*}{ Working status } & Working & 74 & 15.5 \\
& Not working & 404 & 84.5 \\
\hline \multirow{2}{*}{ Marital status } & Married & 327 & 68.4 \\
& Single & 151 & 31.6 \\
\hline Living location & Village & 219 & 45.8 \\
& Town & 137 & 28.7 \\
& City & 122 & 25.5 \\
\hline \multirow{2}{*}{ Income level } & Income equal to expenditure & 258 & 53.9 \\
& Income less than expenditure & 207 & 43.3 \\
& Income more & 13 & 2.7 \\
& expenditure & & \\
\hline
\end{tabular}


Table 2 shows that $34.5 \%$ of the patients visited a psychiatrist at least once, $13.6 \%$ were diagnosed with depression, $13.8 \%$ were not aware of the psychological diagnosis they received, $32.2 \%$ had a medication recommended by the physician, $16.7 \%$ did not know the name of the drug, and $13.2 \%$ had an antidepressant as the recommended drug.

Table 2. Patients' characteristics related to visiting the psychiatrist and psychiatric drug use

\begin{tabular}{|c|c|c|c|}
\hline & & $n$ & $\%$ \\
\hline Visit to a psychiatrist & $\begin{array}{l}\text { Visited } \\
\text { Not visited }\end{array}$ & $\begin{array}{l}165 \\
313\end{array}$ & $\begin{array}{l}34.5 \\
65.5\end{array}$ \\
\hline $\begin{array}{l}\text { Psychiatrist visiting } \\
\text { time }\end{array}$ & $\begin{array}{l}\text { Not visited } \\
1-10 \text { years } \\
\geq 11 \text { years }\end{array}$ & $\begin{array}{l}313 \\
149 \\
16\end{array}$ & $\begin{array}{l}65.5 \\
31.2 \\
3.3\end{array}$ \\
\hline Psychiatric disorder & $\begin{array}{l}\text { I don't have a disease } \\
\text { I don't know the diagnosis } \\
\text { Major depression } \\
\text { Schizophrenia } \\
\text { Anxiety disorder } \\
\text { Substance abuse } \\
\text { Dementia } \\
\text { Sleep disorder } \\
\text { Bipolar affective disorder }\end{array}$ & $\begin{array}{l}313 \\
66 \\
65 \\
1 \\
8 \\
1 \\
13 \\
10 \\
1\end{array}$ & $\begin{array}{l}65.5 \\
13.8 \\
13.6 \\
0.2 \\
1.6 \\
0.2 \\
2.7 \\
2.1 \\
0.2\end{array}$ \\
\hline Psychiatrist suggestion & $\begin{array}{l}\text { Not visited } \\
\text { Use of medication } \\
\text { Hospitalization } \\
\text { No suggestion }\end{array}$ & $\begin{array}{l}313 \\
154 \\
1 \\
10\end{array}$ & $\begin{array}{l}65.5 \\
32.2 \\
0.2 \\
2.1\end{array}$ \\
\hline Type of medication & $\begin{array}{l}\text { Not visited } \\
\text { No medication } \\
\text { I don't know brand name of drug } \\
\text { Antidepressant } \\
\text { Anxiolytic } \\
\text { Antipsychotic } \\
\text { Sedative-hypnotic }\end{array}$ & $\begin{array}{l}313 \\
6 \\
80 \\
63 \\
3 \\
9 \\
4\end{array}$ & $\begin{array}{l}65.5 \\
1.3 \\
16.7 \\
13.2 \\
0.6 \\
1.9 \\
0.8\end{array}$ \\
\hline Duration of drug use & $\begin{array}{l}\text { Not visited } \\
\text { Not use a drug } \\
1 \text { year and ago } \\
2-10 \text { years } \\
\geq 11 \text { years }\end{array}$ & $\begin{array}{l}313 \\
12 \\
96 \\
49 \\
8\end{array}$ & $\begin{array}{l}65.5 \\
2.5 \\
20.1 \\
10.3 \\
1.7\end{array}$ \\
\hline
\end{tabular}

It was also observed that $24.9 \%$ of the patients used an antidepressant at least once in their lifetime, and $16.3 \%$ of the patients were using an antidepressant during the study. In addition, $32 \%$ of the patients were using an antidepressant agent, which was recommended by a psychiatrist and $13.6 \%$ were continuing to use this drug with a diagnosis of depression (Table 2).

Table 3 shows the side effects most commonly encountered by the patients who used an antidepressant at least once in their lifetime: dryness in the mouth (33.6\%), weakness (29.4\%), dysmnesia (29.4\%), lightheadedness (27.7\%), restlessness $(26.1 \%)$, somnolence $(26.1 \%)$, hot flash $(22.7 \%)$, and dizziness (21\%; Table 3).
Table 3. Adverse effects of antidepressant drugs ( $n=119)$

\begin{tabular}{|l|l|l|l|l|}
\multicolumn{2}{l}{} & Present & \multicolumn{3}{l|}{ Absent } \\
\hline Adverse effects & $\mathbf{n}$ & $\%$ & $\mathbf{n}$ & $\%$ \\
\hline Sweating & 19 & 16 & 100 & 84 \\
\hline Dryness in the mouth & 40 & 33.6 & 79 & 66.4 \\
\hline Hot flash & 27 & 22.7 & 92 & 77.2 \\
\hline Lightheadedness & 33 & 27.7 & 86 & 72.3 \\
\hline Flutter & 22 & 18.5 & 97 & 81.5 \\
\hline Urinary retention & 10 & 8.4 & 109 & 91.6 \\
\hline Loss of appetite & 14 & 11.8 & 105 & 88.2 \\
\hline Constipation & 10 & 8.4 & 109 & 91.6 \\
\hline Sleepiness & 20 & 16.8 & 99 & 83.2 \\
\hline Weakness & 35 & 29.4 & 84 & 70.6 \\
\hline Loss of weight & 7 & 5.9 & 112 & 94.1 \\
\hline Loss of sexual desire & 7 & 5.9 & 112 & 94.1 \\
\hline Restlessness & 31 & 26.1 & 88 & 73.9 \\
\hline Increased appetite & 15 & 12.6 & 104 & 87.4 \\
\hline Dysmnesia & 35 & 29.4 & 84 & 70.6 \\
\hline Nausea & 23 & 19.3 & 96 & 80.7 \\
\hline Increased weight & 6 & 5 & 113 & 95 \\
\hline Thoughtfulness & 23 & 19.3 & 96 & 80.7 \\
\hline Irritability & 21 & 17.6 & 98 & 82.4 \\
\hline Somnolence & 31 & 26.1 & 88 & 73.9 \\
\hline Defect of vision & 13 & 10.9 & 106 & 89.1 \\
\hline Dizziness & 25 & 21 & 94 & 79 \\
\hline & & & & \\
\hline
\end{tabular}

Table 4 shows that two-thirds of the patients stated that the symptoms relieved partially, and only $47.1 \%$ of them expressed that they would use the drug along the duration recommended by the physician. Patients who did not use the drug declared the following reasons: fear of addiction (21.6\%), belief that it will not solve their problems (13.7\%), and fear of side effects (17.6\%).

Table 4. Patient thoughts regarding antidepressant drug use

\begin{tabular}{|l|l|l|l|}
\hline Did antidepressant drugs & Symptoms relieved completely & 20 & 16.8 \\
relieve the symptoms of & Symptoms relieved partially & 78 & 65.5 \\
the disease? (n=119) & Symptoms not relieved & 21 & 17.6 \\
\hline $\begin{array}{l}\text { How long do you plan to } \\
\text { use antidepressant drugs? }\end{array}$ & Duration recommended by & 56 & 47.1 \\
(n=119) & the physician & 11 & 9.2 \\
& Duration symptoms relieved & 1 & 0.8 \\
& completely & 2 & 1.7 \\
& At least 6 months & 27 & 22.7 \\
& Discharged from the hospital & 22 & 18.5 \\
\hline Reasons of not using & I don't think to use drug & & \\
antidepressant drugs after & 1 don't know & & \\
discharged (n=51) & Fear of addiction & 11 & 21.6 \\
& I think I'm not crazy & 1 & 2.0 \\
& Belief that it will not solve & 7 & 13.7 \\
their problems & 15 & 29.4 \\
& Think that my disease relieved & 9 & 17.6 \\
& completely & 4 & 7.8 \\
& Fear of side effects & 4 & 7.8 \\
\hline $\begin{array}{l}\text { Who provided } \\
\text { information about }\end{array}$ & I feel worse when use drugs & & \\
antidepressant drugs & Other & \\
(n=119) & Doctors and nurses & 113 & 95 \\
\hline
\end{tabular}


Table 5 shows that $99.2 \%$ of the patients did not know the effects of the drugs, $100 \%$ did not know the time of the onset of the effect, $96.6 \%$ did not know the duration of the treatment, 97.5\% did not know when to discontinue the drug, and $99.2 \%$ did not know the most important side effects which might emerge during the treatment. However, the patients wished to be informed regarding the effects of the drugs (20\%), duration of the treatment $(13.4 \%)$, possible risk of the drug $(13.4 \%)$, drug's effects on the body (7.6\%), methods of coping with the side effects (2.5\%), and addiction potential of the drug $(0.8 \%)$. Additionally, most of the patients requested this information, particularly from physicians and nurses (Table 4).

Table 5. Patients' knowledge related to level of antidepressant drugs $(n=119)$

\begin{tabular}{|l|l|l|l|l|}
\hline & \multicolumn{3}{|l|}{ Know } & \multicolumn{2}{l|}{ Not know } \\
\hline & $\mathbf{n}$ & $\%$ & $\mathbf{n}$ & $\%$ \\
\hline Effects of antidepressant drugs & 1 & 0.8 & 118 & 99.2 \\
\hline Time of the onset of the effect of the drugs & - & - & 119 & 100 \\
\hline Duration of the treatment & 4 & 3.4 & 115 & 96.6 \\
\hline Time of the discontinuing the drugs & 3 & 2.5 & 116 & 97.5 \\
\hline Most important side effects of the drugs & 1 & 0.8 & 118 & 99.2 \\
\hline
\end{tabular}

\section{DISCUSSION}

The objective of our study was to determine the antidepressant use among patients hospitalized in the internal medicine and surgery clinics. In this context, we questioned the prescribing physicians, symptoms aimed to treat with the prescription, awareness about the side effects, the encountered side effects, duration of the treatment, and experienced benefits of the treatment.

One of the findings of our study was that $24.9 \%$ of the patients used an antidepressant agent at least once in their lifetime, and $16.3 \%$ of them were still using an antidepressant. Overall, $32 \%$ of the patients stated that they were using an antidepressant agent according to the recommendation of a psychiatrist.

The studies focused on this topic showed that the rate of the antidepressant use among the hospitalized patients was between $31.4 \%$ and $36.3 \%(4,6)$. In a study conducted in Norway, this rate was $21.7 \%$ among 4,374 patients treated because of opioid addiction (19). It was reported that $10.5 \%$ of 928 patients who visited a psychiatrist used an antidepressant agent, and $73.6 \%$ of these patients received their prescription from a physician who was not a psychiatrist (20). In a study, it was determined that $15.6 \%$ of the 16,780 heart failure patients, who were not diagnosed with clinical depression, used antidepressants (21).

In another study, it was reported that $33 \%$ of 218 heart failure patients used an antidepressant, and $26 \%$ were not diagnosed with depression before the antidepressant use; the drug was prescribed by a second-step physician (16). The most commonly prescribed medication in medical and surgical patients was antidepressant. Also, doctors not specialized in psychiatry were responsible for most prescriptions of antidepressant drugs (17). According to these findings, it might be suggested that the use of antidepressant agents was common abroad as well as in our country, and antidepressant treatment was initiated without prior diagnosis of depression in some patients and probably prescribed by a physician who was not a psychiatrist.

Another finding of our study was that the most common side effects encountered in the patients using an antidepressant at least once in their lifetime were dryness in the mouth, weakness, dysmnesia, lightheadedness, irritability, somnolence, hot flash, and dizziness. In addition to these side effects, we observed that patients experienced side effects, which might negatively affect their quality of life and interindividual relations, such as decreased libido, palpitation, visual impairment, increase in panic symptoms, inattentiveness, irritability, and dizziness.

A research study has reported that the most common side effects, which were experienced by 811 depression patients using antidepressants, were dryness in the mouth, constipation, weight gain, insomnia and diarrhea (8). Another study has determined that $22 \%$ of the patients who had an antidepressant treatment did not comply with the treatment because of the problems, such as weight gain, sexual dysfunction, lack of sexual desire, and weakness (10). The most common side effects of the antidepressant treatments were also headache and nausea (9).

As seen in our study along with studies from abroad, patients often encounter anticholinergic side effects caused by the antidepressants. Moreover, there were other studies demonstrating that extrapyramidal symptoms, such as parkinsonism, acute dystonia, tardive dystonia, and dyskinesia, were seen during the antidepressant treatment (22-24).

The rate of the most common side effect in our study was $33 \%$, although the rate of some side effects was up to $74 \%$ in the studies previously mentioned. As the patients experienced the side effects before the onset of the therapeutic effect and therefore experienced difficulty to comply with the treatment and discontinue the medication, they should be informed that the drug must be administered at tolerable doses; they should also be able to continue with the treatment after the onset of the side effects and be able to manage the side effects during treatment.

One of the most important outcomes of our study was that almost all of the patients had no information regarding the effect of the drug, duration of the effect, treatment duration, time of treatment discontinuation, and the most important side effects during the treatment. However, they expressed that they wanted to receive information about the effects of the drugs, duration of the treatment, about the potential harms of the drugs, effects to the body, management of the side effects, and the addictive potential of the drugs. These results might be related to the lack of briefing of the patients 
by the physicians and nurses or to the lack of interest of the patients.

We accessed only one study conducted in Turkey, which would contribute significantly to this topic. Striking results were obtained by this descriptive study, which the researchers conducted by accessing 120 family physicians working in 6 different districts of Istanbul. Although $80.8 \%$ of the family physicians suggested that they had sufficient information and experience to diagnose depression, the investigators determined $47.5 \%$ of them were not sufficiently informed about the treatment of depression. In the same study, only $1.5 \%$ of the physicians were able to identify all of the depression symptoms, and $89.2 \%$ expressed that they needed regular training about the use of the antidepressants in the treatment (18).

In a study conducted abroad, $72.0 \%$ of 137 physicians, who were prescribing antidepressants, stated that they recommended the patients to use the drugs for least 6 months (25). In the same study, 401 patients were questioned about their treatment, and $34.0 \%$ of them stated that their physicians recommended them to use the medication for at least 6 months, and 56\% stated that they did not get any explanation in this regard. In addition, patients who informed their physicians about the experienced side effects had a higher compliance rate than those who did not. These results showed that the patients should be trained regarding the effects, side effects, management of the side effects, and duration of the treatment to achieve a good compliance to the treatment period.

\subsection{Study Limitations}

All data were obtained from the patients hospitalized only in one hospital. All data were based on the personal declaration of the patients.

\section{CONCLUSION}

Similar to studies mentioned previously, our study showed that the patients were not adequately informed about the antidepressant use. The physicians and nurses should brief the patients. In this context, enhancement of the knowledge of the prescribing physicians and practicing nurses regarding the antidepressant agents might be useful.

These findings showed that informing the patients about the drug's effects, onset of the effect, duration of the treatment, time of treatment discontinuation, and the most important side effects and their management was essential for compliance to treatment and for benefitting from the drug therapy. It might be recommended that the knowledge level of the practicing nurses and physicians (except psychiatrists) about the antidepressant agents used by the patients should be evaluated, and if necessary, in-service training on the required information should be organized so that they are capable of fulfilling the information needs of the patients
Conflict of Interest: No conflict of interest was declared by the authors.

Financial Disclosure: The authors declared that this study has received no financial support.

\section{REFERENCES}

[1] Urhan ÜB. Türkiye' de Antidepresan Kullanımları Artıyor mu? Sosyo-Psikolojik Göstergeler Çerçevesinde Bir Değerlendirme. Türkiye Ekonomi Politikaları Araştırma Vakfı (TEPAV) Girişimcilik Enstitüsü Yayınları, 2010 (Turkish).

[2] Aydın N, Çetin M, Kurt E, Savaş H, Açıkel C, Kılıç S, Başoğlu C, Türkçapar H. A report by Turkish Association for Psychopharmacology on the psychotropic drug usage in Turkey and medical, ethical and economical consequences of current applications. Bull. Clin. Psychopharmacol. 2013; 23: 390-402.

[3] Canan F, Koçer E, İçmeli C, Özçetin A, Ataoğlu A. Evaluation of psychiatric consultations of medical inpatients in a university hospital. Düzce Med. J. 2008; 1: 22-27.

[4] Mayda H, Güzel Hi, Görücü Y, Bağcıoğlu E. The evaluation of psychiatry consultation requested in a university hospital. J. Clin. Anal. Med. 2015; 6(Suppl 2): 177-180.

[5] Uyar B, Gürgen F. The assessment of psychiatric consultations in a university hospital. J Clin Psychiatry 2015; 18: 24-28.

[6] Gürçay E, Ayhan N, Gümüşok S, Ekşioğlu E, Tamkan U, Çakcı A. Evaluation of consultation liason psychiatry in physical therapy and rehabilitation patients. J. PMR Sci. 2008; 3: 124-128.

[7] Kökçam I, Dilek N. Psychiatric consultations of patients who treated in the dermatology clinic. Firat University Med. J.Health Sci. 2010; 24: 21-24.

[8] Uher R, Farmer A, Henigsberg N, Rietschel M, Mors O, Maier W, Kozel D, Hauser J, Souery D, Placentino A, Strohmaier J, Perroud N, Zobel A, Rajewska-Rager A, Dernovsek MZ, Larsen ER, Kalember P, Giovannini C, Barreto M, McGuffin P, Aitchison KJ. Adverse reactions to antidepressants. Br. J. Psychiatry 2009; 195: 202-210.

[9] Anderson HD, Pace WD, Libby AM, West DR, Valuck RJ. Rates of 5 common antidepressant side effects among new adult and adolescent cases of depression: a retrospective US claims study. Clin. Ther. 2012; 34: 113-123.

[10] Ashton AK, Jamerson BD, Weinstein WL, Wagoner C. Antidepressant-related adverse effects impacting treatment compliance: results of a patient survey. Curr. Ther. Res. Clin. Exp. 2005; 66: 96-106.

[11] Al B, Orak M, Üstündağ M, Söğüt Ö. Characteristics of suicides cases in Batman, South East of Turkey. J. Med. Sci. 2010; 30: 65-72.

[12] Uludağ Ö, Tutak A, Doğukan M, Kaya R, Tutak AŞ, Çelik M. Characteristics of poisoning cases in Adıyaman city. Dicle Med. J. 2015; 42: 284-288.

[13] Yıldıztepe E, Aksay NH, Demir Ö, Arıcı A, Oransay K, Evcim S, et al. Kalkan Ş, MD, Tunçok Y. Analysis of the year 2007 data of Dokuz Eylül University drug and poison information center, Turkey. Türkiye Klinikleri J Med Sci 2010; 30: 1622-1630.

[14] Aygin D, Cengiz H. Drug administration errors and the responsibility of a nurse. Ş.E.E.A.H. Tıp Bülteni 2011; 45: 110114.

[15] Engin E, Ergün G. Depresyon. Ruh Sağlığı ve Hastalıkları Hemşireliği: Bakım Sanatı (Ed. O. Çam, E. Engin). İstanbul: İstanbul Tıp Kitabevi, 2014.wp. 333-365 (Turkish). 
[16] Hartz I, Bramness JG, Skurtveit S. Prescription of antidepressants to patients on opioid maintenance therapy a pharmacoepidemiological study. Norsk. Epidemiologi. 2011; 21: 77-83.

[17] Mojtabai R, Olfson M. National Patterns in Antidepressant Treatment by Psychiatrists and General Medical Providers: Results From the National Comorbidity Survey Replication. J. Clin. Psychiatry 2008; 69: 1064-1074.

[18] Brouwers C, Christensen SB, Damen NL, Denollet J, TorpPedersen C, Gislason GH, Pederson SS. Antidepressant use and risk for mortality in 121,252 heart failure patients with or without a diagnosis of clinical depression. Int. J. Cardiol. 2016; 203: 867-873.

[19] Jimenez JA, Redwine LL, Rutledge TR, Dimsdale JE, Pung MA, Ziegler MG, Greenberg BH, Mills PJ. Depression ratings and antidepressant use among outpatient heart failure patients: implications for the screening and treatment of depression. Int. J. Psychiatry Med. 2012; 44: 315-334.
[20] Shirama FH, Miasso Al. Consumption of psychiatric drugs by patients of medical and surgical clinics in a general hospital. Rev. Latino-Am. Enfermagem 2013; 21: 948-955.

[21] Bayrak A, Çetin B, Meteris H, Kesebir S. Parkinsonizm secondary to duloxetine use: a case report. North Clin. Istanb. 2015; 2: 243-246.

[22] Dixit S, Khan SA, Azad S. A case of SSRI induced irreversible parkinsonizm. J. Clin. Diagn. Res. 2015; 9: 1-2.

[23] Huh L, Lee BJ. Efficacy of aripiprazole in antidepressantsinduced tardive dystonia and tardive dyskinesia: a case report. Psychiatr. Danub. 2015; 27: 195-197.

[24] Yıldırım A, Gönüllü OG, Eradamlar N, Erkıran M. Factors affecting prescribtion of antidepressant medications by family physicians in Istanbul province. J. Psychiatr. Neurol. Sci. 2014; 27: 242-249.

[25] Bull SA, Hu XH, Hunkeler EM, Lee JY, Ming EE, Markson $L E$, Fireman B. Discontinuation of use and switching of antidepressants: influence of patient-physican communication. JAMA 2002; 288: 1403-1409. 